\title{
Resistance exercise training reduces arterial reservoir pressure in older adults with prehypertension and hypertension
}

\author{
Kevin S Heffernan ${ }^{1}$, Eun Sun Yoon ${ }^{2}$, James E Sharman ${ }^{3}$, Justin E Davies ${ }^{4}$, Yuan-Ta Shih ${ }^{5}$, Chen-Huan Chen ${ }^{6,7}$, \\ Bo Fernhall ${ }^{8}$ and Sae Young $\mathrm{Jae}^{2}$
}

We examined changes in central blood pressure (BP) following resistance exercise training (RET) in men and women with prehypertension and never-treated hypertension. Both Windkessel theory and wave theory were used to provide a comprehensive examination of hemodynamic modulation with RET. Twenty-one participants (age $61 \pm 1$ years, $n=6$ male; average systolic blood pressure (SBP)/diastolic blood pressure $(\mathrm{DBP})=138 / 84 \mathrm{~mm} \mathrm{Hg}$ ) were randomized to either 12 weeks of $\mathrm{RET}(n=11)$ or an inactive control group. Central BP and augmentation index (Alx) were derived from radial pressure waveforms using tonometry and a generalized transfer function. A novel reservoir-wave separation technique was used to derive excess wave pressure (related to forward and backward traveling waves) and reservoir pressure (related to the capacitance/Windkessel properties of the arterial tree). Wave separation using traditional impedance analysis and aortic flow triangulation was also applied to derive forward wave pressure $(\mathrm{Pf})$ and backward wave pressure $(\mathrm{Pb})$. There was a group-by-time interaction $(P<0.05)$ for central BP as there was a significant $\sim 6 \mathrm{~mm} \mathrm{Hg}$ reduction in SBP and $\sim 7 \mathrm{~mm} \mathrm{Hg}$ reduction in DBP following RET with no change in the control condition. There were also group-by-time interactions $(P<0.05)$ for $\mathrm{Pf}$, excess wave pressure and reservoir pressure attributable to reductions in these parameters in the RET group concomitant with slight increases in the control group. There was no change in Alx or $\mathrm{Pb}(P>0.05)$. RET may reduce central $\mathrm{BP}$ in older adults with hypertension and prehypertension by lowering $\mathrm{Pf}$ and reservoir pressure without affecting pressure from wave reflections.

Hypertension Research (2013) 36, 422-427; doi:10.1038/hr.2012.198; published online 13 December 2012

Keywords: augmentation index; blood pressure; exercise; hemodynamic

\section{INTRODUCTION}

Although aerobic/endurance exercise has repeatedly been shown to reduce blood pressure (BP) in numerous cohorts, ${ }^{1}$ resistance exercise training (RET) still remains an understudied and underappreciated exercise modality for BP modification. RET is currently recommended for general health promotion in persons with cardiovascular $(\mathrm{CV})$ disease $^{2}$ and several studies note modest but clinically significant reductions in brachial BP with RET. ${ }^{3}$ Yet despite these favorable reductions in $\mathrm{BP}$, current professional guidelines do not acknowledge RET as a therapeutic option for the management of hypertension in older adults. ${ }^{4}$

RET may reduce central BP (that is carotid, aortic), ${ }^{5,6}$ and this is important given that central BP is more predictive of target organ damage, CV morbidity and CV mortality compared with traditionally measured brachial BP. ${ }^{7-10}$ The change in contour of the central BP waveform with aging and in the presence of hypertension is due to a number of hemodynamic factors including increased forward wave pressure $(\mathrm{Pf})$, increased pressure from wave reflections, increased arterial impedance and reduced arterial compliance. ${ }^{11,12}$ The capacitance or Windkessel function of the large central arteries (that is the arterial reservoir) also has a significant role in modulating central BP with aging. ${ }^{13,14}$ During left ventricular contraction, blood enters the aorta faster than it can leave; this increasing volume distends the aorta, increasing the reservoir pressure. ${ }^{13}$ With advancing age and subsequent loss of arterial compliance, pressure in the arterial reservoir rises more rapidly for a similar increase in volume, having a significant impact on central BP. ${ }^{13}$ An examination of this novel hemodynamic parameter may lead to greater understanding of the mechanism(s) responsible for BP reduction with RET, whereas simultaneously providing much needed

${ }^{1}$ Human Performance Laboratory, Department of Exercise Science, Syracuse University, Syracuse, NY, USA; ${ }^{2}$ Department of Sports Informatics, University of Seoul, Seoul, South Korea; ${ }^{3}$ Menzies Research Institute Tasmania, University of Tasmania, Hobart, Australia; ${ }^{4}$ International Center for Circulatory Health, St Mary's Hospital Campus, London, UK; ${ }^{5}$ Department of Biomedical Engineering, Chung Yuan Christian University, Chung-Li, Taiwan; ${ }^{6}$ Department of Medical Research and Education, Taipei Veterans General Hospital, Taipei, Taiwan; ${ }^{7}$ Departments of Medicine and Public Health, Cardiovascular Research Center, National Yang-Ming University, Taipei, Taiwan and ${ }^{8}$ Department of Kinesiology and Nutrition, University of Illinois-Chicago, Chicago IL, USA

Correspondence: Dr KS Heffernan, Human Performance Laboratory, Department of Exercise Science, Syracuse University, 820 Comstock Avenue, Syracuse, NY 13244 , USA. E-mail: ksheffer@syr.edu

Received 13 August 2012; revised 29 September 2012; accepted 11 October 2012; published online 13 December 2012 
exculpatory evidence on the use of RET to abrogate CV risk in at-risk cohorts such as older adults with prehypertension.

Current estimates suggest that 70 million Americans are prehypertensive. ${ }^{15,16}$ Prehypertensive individuals are 11 times more likely to develop hypertension, ${ }^{17}$ increasing $\mathrm{CV}$ risk substantially. ${ }^{18,19}$ Moreover, preferential elevation of central BP in prehypertensive adults represents an intermediate phenotype in the pathogenesis of hypertension, ${ }^{20}$ as it is well established that individuals with hypertension have elevated central BP. ${ }^{21}$ Efficacy of RET to reduce central BP in prehypertensive and hypertensive older adults and the mechanisms by which it may do so merits further scrutiny.

The purpose of this study was to examine the effect of RET on central BP in older adults with prehypertension and newly diagnosed/ never-treated hypertension. We sought to interrogate changes in the contour of the BP waveform using two different complementary hemodynamic theories: (1) reservoir theory (lumped-parameter model that examines the interaction of capacitance, compliance and resistance on the arterial system) and (2) wave-only theory (examines the interaction of outgoing/forward traveling pressure waves from the heart and reflected/backward traveling pressure waves from peripheral bifurcations and arterioles). Combining these approaches will allow for a comprehensive examination of pulse contour changes with RET. On the basis of our previous work ${ }^{5,6}$ we hypothesized that RET would reduce central BP in prehypertensive and hypertensive men and women, and this would be related to a reduction in arterial reservoir pressure and not pressure from wave reflections.

\section{METHODS}

\section{Subjects}

Prehypertensive $(n=11)$ and newly diagnosed/never-treated hypertensive $(n=10)$ older adults participated in this study. All subjects were non-smokers and did not have any known CV, metabolic or inflammatory diseases, nor use $\mathrm{CV}$ medications or anti-inflammatory substances of any kind. None engaged in regular aerobic or resistance exercise. The subjects were randomly assigned to either 12 weeks of RET $(n=11)$ or an inactive control group $(n=10)$. The subjects were informed of the experimental procedures and possible risks involved in the present study, their right to withdraw from the study at any time and the measures taken to protect privacy. Written consent was obtained from all participants and all aspects of this study were conducted in accordance with ethical standards laid down in the Declaration of Helsinki.

\section{Study design}

Previous work has noted reductions in central BP following RET of $\sim 6 \mathrm{~mm} \mathrm{Hg}$ (effect size $=0.5)$ in older prehypertensive adults. ${ }^{5}$ Sample size was thus determined from this study with the goal of seeing a similar reduction in central BP (power $=0.8$ for a one-tailed test). Participants reported to the laboratory following an overnight fast. Hemodynamics were assessed following $15 \mathrm{~min}$ of supine rest. This was followed by assessment of body fat using bioelectric impedance analysis (Biospace, Inbody, Seoul Korea). A blood sample was then obtained from venipuncture and analyzed in a clinical laboratory using standard enzymatic techniques for blood lipids, fasting glucose and C-reactive protein. All measures were repeated following the 12 -week intervention period.

Following baseline testing only, all participants underwent measurement of 24-hour BP with ambulatory monitoring to corroborate hypertensive status (previously established by repeated physician assessment). An automated ambulatory BP monitor (SpaceLabs 90207, SpaceLabs Medical, Redmond, WA, USA) was used for ambulatory BP measurements; measured every $30 \mathrm{~min}$ for daytime and $60 \mathrm{~min}$ for nighttime recordings. Discrimination of the daytime and the nighttime was obtained from individual self-reported sleep time. Subjects were encouraged to continue their usual daily activities and sleep patterns during the monitoring period but were instructed to avoid exercise and alcohol consumption.
Treadmill cardiopulmonary exercise testing was performed on a separate day (24 $\mathrm{h}$ after BP assessment) using a modified Bruce protocol. Expired gases were collected breath-by-breath using a one-way valve and analyzed using a metabolic cart (Q-stress/Trueone 2400, US). Peak oxygen uptake $\left(\mathrm{ml} \mathrm{kg}^{-1}\right.$ $\min ^{-1}$ ) was defined as the highest value recorded during the test using established criteria and taken as an index of cardiorespiratory fitness.

\section{Resistance exercise training}

RET was supervised by a personal trainer and performed 3 days a week. RET consisted of nine machine-based resistance exercises, four upper body (chest press, latissimus dorsi pulldown, back row, biceps curl), three lower body (leg press, leg extension and leg curl) and two core (abdominal crunch and lower back extension) exercises. The load was initially set at $40 \%$ of previously determined 1-RM values for upper body and $60 \%$ for lower body exercises in accordance with American Heart Association recommendations. ${ }^{2}$ Two sets of 12-15 repetitions were performed during each session. The load was progressively increased by $5 \%$ every 3 weeks or when subjects could easily perform 15 repetitions.

\section{Pulse wave analysis}

Resting BP was measured in duplicate in the brachial artery using an automated oscillometric device and the average systolic and diastolic values were used for subsequent analyses. Radial artery pressure waveforms were obtained in duplicate from a 10-s epoch using applanation tonometry and a high-fidelity strain-gauge transducer (Millar Instruments, Houston, TX, USA). Using a generalized validated transfer function, ${ }^{22,23}$ a central aortic pressure waveform was reconstructed (SphygmoCor, AtCor Medical, Sydney, NSW, Australia). Mean pressure was derived from integrating the area under the central BP waveform. Left ventricular systolic ejection duration was taken as the time from the foot of the pressure wave upstroke to the incisura of the dicrotic notch. Augmented pressure was defined as the difference between central systolic blood pressure (SBP) and the pressure at the primary wave peak $\left(P_{1}\right) . P_{1}$ height was defined as the pressure at the first inflection point. Aortic pulse wave travel time (Tr) was determined from the time from the initial upstroke of the pressure wave to $P_{1}$. The systolic pressure tension-time integral and the diastolic pressure tension-time index were quantified to examine systolic-to-diastolic shifts in the proportion of pressure comprising the overall pressure waveform. Augmentation index (AIx) was calculated as the difference between the early- and late-systolic peaks of the arterial waveform to the total pulse pressure $(\mathrm{PP})$ expressed as a percentage $\left(P_{2}-P_{1} / \mathrm{PP} \times 100\right)$. The intraclass correlation coefficient calculated for test-retest reproducibility for synthesized aortic SBP and AIx in this laboratory is $>0.95$.

The aortic pressure waveform was then separated into its forward (Pf) and reflected $(\mathrm{Pb})$ components to calculate the transit time-independent parameters of wave reflection magnitude using a flow triangulation method as originally proposed by Westerhof et al.,24 and later used by Wang et al. ${ }^{25}$ Briefly, the shape of the truncated aortic flow wave can be estimated by using a triangular pseudoflow waveform. Flow is assumed to be zero during diastole and thus the flow waveform is constructed from interpolating a line from the timing of the onset of the pressure waveform foot to the inflection point/ waveform shoulder (signaling arrival of the reflected pressure wave and approximating timing of peak aortic outflow) to end systole or the incisura of the dicrotic notch (Figure 1). The forward and backward components of the pressure wave were constructed using the following equations:

$$
\begin{aligned}
& \operatorname{Pf}(\mathrm{t})=[\operatorname{Pm}(\mathrm{t})+\mathrm{Zc} \times \mathrm{F}(\mathrm{t})] / 2 \\
& \operatorname{Pb}(\mathrm{t})=[\operatorname{Pm}(\mathrm{t})-\mathrm{Zc} \times \mathrm{F}(\mathrm{t})] / 2
\end{aligned}
$$

where $\operatorname{Pm}(t)$ is the synthesized aortic pressure wave, $F(t)$ is the approximated triangular-shaped flow wave, $\operatorname{Pf}(\mathrm{t})$ is the forward pressure component, and $\mathrm{Pb}(\mathrm{t})$ is the backward pressure component (Figure 1). Because calculation of Pf and $\mathrm{Pb}$ involves the product of flow and characteristic impedance $(\mathrm{Zc})$, which itself has flow in the denominator, calibration of the flow waveform is not needed (that is independent of flow calibration). ${ }^{24,25} \mathrm{Pf}$ and $\mathrm{Pb}$ are the pressure amplitudes of $\operatorname{Pf}(\mathrm{t})$ and $\mathrm{Pb}(\mathrm{t})$, respectively. For a detailed description of wave separation and impedance analyses, the reader is referred to the original works and reviews cited herein. ${ }^{26-29}$ The reflection index, analogous to the AIx and 


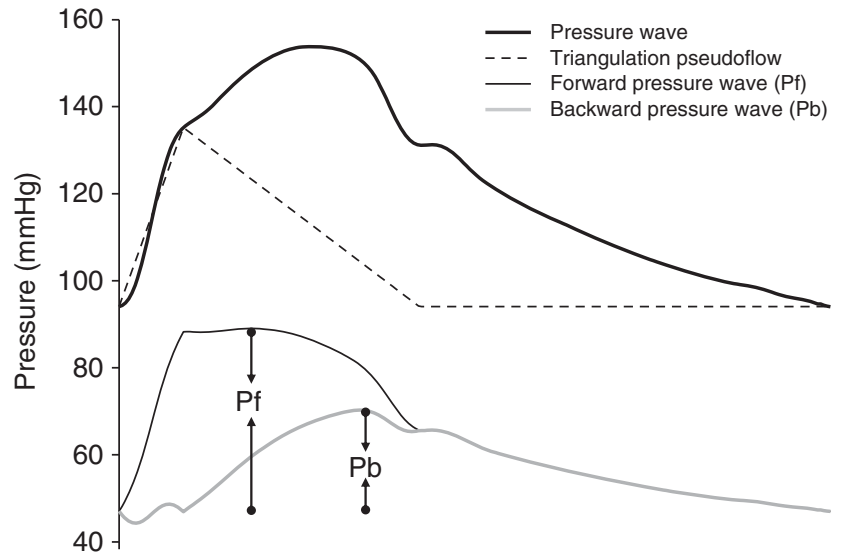

Figure 1 Sample wave separation using impedance analysis and a pseudoflow waveform approximated via triangulation from a central pressure waveform.

defined as the ratio of the reflected wave to the sum of the forward and reflected wave was calculated as the ratio of $\mathrm{Pb} / \mathrm{Pf}+\mathrm{Pb} \times 100 .^{24,25} \mathrm{Pf}$ and $\mathrm{Pb}$ determined from this technique have previously been shown to be similar to values obtained using true aortic flow waves via invasive and non-invasive recordings. ${ }^{24,25}$

When aortic inflow exceeds outflow, the aorta is distended causing a rise in pressure. This arterial reservoir pressure was calculated by separating the aforementioned radial pressure waves into two components by iteration of the equation (below) and by fitting a monoexponential function to the falling pressure during diastole. ${ }^{13,30}$

$$
P_{\text {reservoir }}-P_{\infty}=e^{-(a+b) t} \int_{0}^{t}\left[a P\left(t^{\prime}\right)+b P_{\infty}\right] e^{(a+b) t^{\prime}} d t^{\prime}+\left(P_{d}-P_{\infty}\right) e^{-(a+b) t}
$$

The excess wave pressure (pressure attributed to forward and backward traveling waves) was derived by the subtraction of arterial reservoir pressure from total pressure (Figure 2). ${ }^{31}$ These waveform components provide information that is incremental to SBP and diastolic blood pressure (DBP)time integrals. All of the reservoir and excess wave pressures are quoted with DBP subtracted. $P_{\text {reservoir }}$ is reservoir pressure, $P_{\infty}$ is the asymptotic pressure, $P_{d}$ is the measured DBP at $t=0, b=1 / R C$, where $R=$ resistance and $C=$ compliance of the system; $a$ is a rate constant that can be determined by fitting during the diastolic period.

\section{Statistical analysis}

The average values obtained from the two radial measures was used for all subsequent analyses. Baseline comparisons were made using analysis of variance for continuous variables and $\chi^{2}$-tests for categorical variables. Analysis of variance with repeated measures ( 2 groups $\times 2$ time points) was used to analyze the main outcome variables. If significant group-by-time interactions were detected, post hoc comparisons were made with $t$-tests. Analysis of covariance with repeated measures was also performed with sex as a covariate. Associations of interest were examined using Pearson's and Spearman's correlation coefficients. Change scores were computed as postvaluesprevalues. All statistical analyses were performed at the 0.05 level of significance and carried out by using IBM SPSS version 19 (IBM, Chicago, IL, USA).

\section{RESULTS}

All participants successfully completed the exercise intervention (compliance to sessions $>90 \%$ ) without any CV complications. There were no group differences in age, sex (RET: $n=2$ men $v$ s. Control: $n=4$ men; $P>0.05$ ) or 24 -hour BP at baseline (Table 1). Prevalence of hypertension ( $n=5$ per group) and prehypertension ( $n=6$ in RET

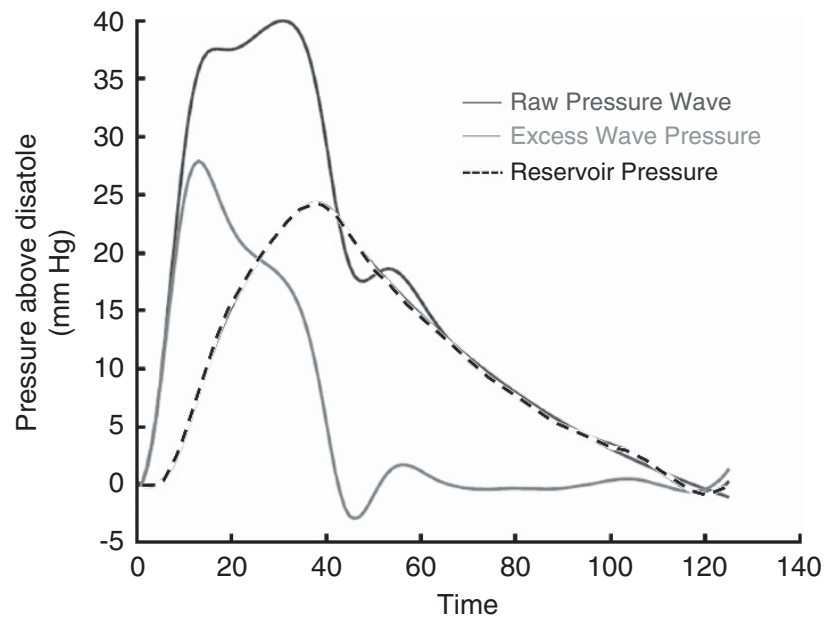

Figure 2 Example of the reservoir wave separation technique obtained from a peripheral (radial) pressure waveform. Values are expressed after subtracting DBP.

\section{Table 1 Subject descriptive characteristics}

\begin{tabular}{lcc}
\hline Variable & RET & Control \\
\hline Age (years) & $60 \pm 2$ & $63 \pm 2$ \\
Height (m) & $1.6 \pm 0.02$ & $1.6 \pm 0.02$ \\
& & \\
Ambulatory 24- $h$ BP & & \\
SBP mean (mm Hg) & $135 \pm 5$ & $136 \pm 5$ \\
SBP day ( $\mathrm{mm} \mathrm{Hg})$ & $141 \pm 5$ & $140 \pm 5$ \\
SBP night $(\mathrm{mm} \mathrm{Hg})$ & $130 \pm 5$ & $132 \pm 5$ \\
DBP mean $(\mathrm{mm} \mathrm{Hg})$ & $81 \pm 3$ & $84 \pm 3$ \\
DBP day (mm Hg) & $84 \pm 3$ & $86 \pm 3$ \\
DBP night $(\mathrm{mm} \mathrm{Hg})$ & $78 \pm 3$ & $81 \pm 3$ \\
\hline
\end{tabular}

Abbreviations: $\mathrm{BP}$, blood pressure; $\mathrm{DBP}$, diastolic blood pressure; RET, resistance exercise training; SBP, systolic blood pressure.

vs. 5 in control) was similar between groups $(P>0.05)$. RET significantly increased muscular strength (1-RM) for all exercises (data not shown, $P<0.05$ ) confirming a training effect. There was no change in muscular strength in the control group or cardiorespiratory fitness in either group $(P>0.05)$.

There were similar reductions in glucose in both RET and control groups (Table $2, P<0.05$ ). A group-by-time interaction was detected for low-density lipoprotein cholesterol $(P<0.05)$ as there was a nonsignificant increase in LDL-cholesterol in the RET group $(P>0.05)$ coupled with a non-significant reduction in low-density lipoprotein cholesterol in the control group $(P>0.05)$.

There were no baseline group differences in any hemodynamic parameter $(P>0.05)$. There were significant reductions in brachial SBP, aortic SBP and mean pressure in the RET group compared with the control group (Table 3, $P<0.05$ ). Group-by-time interactions were also detected for primary wave pressure $\left(P_{1}\right)$ height, Pf, excess wave pressure and reservoir pressure (Table $3, P<0.05$ ) as there were reductions in the RET group coupled with slight increases in the control group $(P<0.05$ for all). There were no significant changes in augmented pressure, $\mathrm{Tr}, \mathrm{AIx}, \mathrm{Pb}$ or reflection index $(P>0.05)$. Adjusting for changes in low-density lipoprotein cholesterol, and/or glucose with analysis of covariance had no effect on aforementioned 
Table 2 Change in CV risk factors and metabolic parameters

\begin{tabular}{|c|c|c|c|c|}
\hline \multirow[b]{2}{*}{ Variable } & \multicolumn{2}{|c|}{ RET } & \multicolumn{2}{|c|}{ Control } \\
\hline & Pre & Post & Pre & Post \\
\hline Body mass index $\left(\mathrm{kg} \mathrm{m}^{-2}\right)$ & $24 \pm 1$ & $24 \pm 1$ & $26 \pm 1$ & $26 \pm 1$ \\
\hline Body fat (\%) & $30 \pm 2$ & $30 \pm 2$ & $31 \pm 2$ & $31 \pm 2$ \\
\hline $\mathrm{VO}_{2} \max \left(\mathrm{ml} \mathrm{kg}^{-1} \mathrm{~min}^{-1}\right)$ & $27 \pm 6$ & $28 \pm 5$ & $23 \pm 4$ & $23 \pm 4$ \\
\hline Glucose $\left(\mathrm{mg} \mathrm{dL}^{-1}\right)^{\mathrm{a}}$ & $102 \pm 11$ & $97 \pm 8$ & $104 \pm 12$ & $95 \pm 8$ \\
\hline Total cholesterol $\left(\mathrm{mgdL}^{-1}\right)$ & $233 \pm 11$ & $245 \pm 10$ & $212 \pm 11$ & $208 \pm 11$ \\
\hline LDL cholesterol $\left(\mathrm{mgdL}^{-1}\right)^{\mathrm{b}}$ & $141 \pm 11$ & $151 \pm 10$ & $134 \pm 12$ & $122 \pm 11$ \\
\hline HDL cholesterol (mg dL $\left.{ }^{-1}\right)$ & $57 \pm 5$ & $61 \pm 4$ & $51 \pm 5$ & $53 \pm 4$ \\
\hline Triglycerides $\left(\mathrm{mg} \mathrm{dL}^{-1}\right)$ & $148 \pm 22$ & $146 \pm 23$ & $130 \pm 23$ & $124 \pm 24$ \\
\hline $\begin{array}{l}\text { C-reactive protein } \\
\left(\mathrm{mg} \mathrm{dL}^{-1}\right)\end{array}$ & $0.71 \pm 0.45$ & $0.30 \pm 0.28$ & $1.11 \pm 0.48$ & $0.84 \pm 0.30$ \\
\hline
\end{tabular}

Abbreviations: CV, cardiovascular; HDL, high-density lipoprotein; LDL, low-density lipoprotein; $\mathrm{RET}$, resistance exercise training; $\mathrm{VO}_{2} \mathrm{max}$, maximal oxygen uptake.

aTime effect $(P<0.05)$.

${ }^{b}$ Group-by-time interaction $(P<0.05)$.

Table 3 Change in pressure waveform parameters

\begin{tabular}{|c|c|c|c|c|}
\hline \multirow[b]{2}{*}{ Variable } & \multicolumn{2}{|c|}{$R E T$} & \multicolumn{2}{|c|}{ Control } \\
\hline & Pre & Post & Pre & Post \\
\hline Brachial SBP $(\mathrm{mm} \mathrm{Hg})^{a}$ & $140 \pm 4$ & $134 \pm 4$ & $136 \pm 4$ & $139 \pm 4$ \\
\hline Brachial DBP $(\mathrm{mm} \mathrm{Hg})^{\mathrm{b}}$ & $83 \pm 2$ & $77 \pm 2$ & $86 \pm 2$ & $82 \pm 2$ \\
\hline Aortic SBP (mm Hg) & $134 \pm 5$ & $129 \pm 4$ & $130 \pm 5$ & $133 \pm 4$ \\
\hline Aortic DBP $(\mathrm{mm} \mathrm{Hg})^{b}$ & $84 \pm 2$ & $77 \pm 2$ & $87 \pm 2$ & $84 \pm 2$ \\
\hline Mean pressure $(\mathrm{mm} \mathrm{Hg})^{a, b}$ & $106 \pm 3$ & $99 \pm 3$ & $105 \pm 3$ & $105 \pm 3$ \\
\hline $\begin{array}{l}\text { Primary wave height } \\
(\mathrm{mm} \mathrm{Hg})^{\mathrm{a}}\end{array}$ & $32 \pm 2$ & $30 \pm 2$ & $28 \pm 2$ & $30 \pm 2$ \\
\hline $\begin{array}{l}\text { Augmented pressure } \\
(\mathrm{mm} \mathrm{Hg})\end{array}$ & $18 \pm 2$ & $20 \pm 2$ & $17 \pm 2$ & $19 \pm 2$ \\
\hline Augmentation index (\%) & $36 \pm 3$ & $38 \pm 3$ & $37 \pm 3$ & $36 \pm 3$ \\
\hline $\begin{array}{l}\text { Systolic ejection duration } \\
\text { (ms) }\end{array}$ & $337 \pm 7$ & $336 \pm 5$ & $346 \pm 7$ & $343 \pm 6$ \\
\hline Time to reflection (ms) & $135 \pm 3$ & $132 \pm 3$ & $136 \pm 3$ & $137 \pm 3$ \\
\hline Systolic TTI (AUC) $)^{a}$ & $2552 \pm 84$ & $2397 \pm 83$ & $2465 \pm 93$ & $2483 \pm 92$ \\
\hline Diastolic TTI (AUC) ${ }^{\mathrm{a}}$ & $3781 \pm 114$ & $3538 \pm 109$ & $3803 \pm 119$ & $3829 \pm 114$ \\
\hline $\mathrm{Pf}(\mathrm{mm} \mathrm{Hg})^{\mathrm{a}}$ & $33 \pm 2$ & $30 \pm 2$ & $29 \pm 2$ & $32 \pm 2$ \\
\hline $\mathrm{Pb}(\mathrm{mm} \mathrm{Hg})$ & $20 \pm 2$ & $21 \pm 2$ & $18 \pm 2$ & $20 \pm 2$ \\
\hline Reflection index (\%) & $38 \pm 3$ & $39 \pm 4$ & $39 \pm 5$ & $38 \pm 4$ \\
\hline $\begin{array}{l}\text { Reservoir pressure } \\
(\mathrm{mm} \mathrm{Hg})^{\mathrm{a}}\end{array}$ & $34 \pm 2$ & $31 \pm 2$ & $32 \pm 2$ & $35 \pm 2$ \\
\hline $\begin{array}{l}\text { Excess wave pressure } \\
(\mathrm{mm} \mathrm{Hg})^{a}\end{array}$ & $37 \pm 3$ & $34 \pm 3$ & $35 \pm 3$ & $39 \pm 3$ \\
\hline
\end{tabular}

Abbreviations: AUC, area under the curve; DBP, diastolic blood pressure; $\mathrm{Pb}$, backward wave pressure; $\mathrm{Pf}$, forward wave pressure; RET, resistance exercise training; SBP, systolic blood pressure; $T$ TT, tension-time integral. aGroup-by-time interaction $(P<0.05)$

bTime effect $(P<0.05)$.

changes in hemodynamic parameters. Adjusting for sex also had no effect on aforementioned group-by-time interactions.

Change in aortic systolic pressure was associated with change in $P_{1}$ height $(r=0.56, P<0.05)$, change in $\operatorname{Pf}(r=0.73, P<0.05)$, change in excess wave pressure $(r=0.67, P<0.05)$ and change in reservoir pressure $(r=0.80, P<0.05)$ but not change in $\mathrm{AIx} \quad(r=0.04$, $P>0.05)$, reflection index $(r=0.02, P>0.05)$ or $\mathrm{Pb}(0.26, P>0.05)$.
Change in aortic DBP was associated with change in reservoir pressure only $(r=0.46, P<0.05)$. Change in aortic DBP was not associated with change in $P_{1}$ height, excess wave pressure, $\mathrm{Pf}, \mathrm{Pb}, \mathrm{AIx}$ or reflection index $(P>0.05$ for all).

\section{DISCUSSION}

Consistent with previous reports, we noted that RET had a favorable effect on BP, lowering both absolute brachial and aortic SBP and DBP by $6-7 \mathrm{~mm} \mathrm{Hg}$. ${ }^{5,6}$ The reductions in BP found in the present study are clinically relevant, as a reduction in brachial SBP of $6 \mathrm{~mm} \mathrm{Hg}$ on a population level may reduce $\mathrm{CV}$ morbidity by as much as $10 \%{ }^{32}$ Similarly, according to a recent meta-analysis, a reduction in aortic SBP of $10 \mathrm{~mm} \mathrm{Hg}$ was associated with an $\sim 9 \%$ reduction in risk for CV events. ${ }^{33}$ Thus, RET may be a useful lifestyle intervention to abrogate CV risk via reducing both peripheral and central BP in older prehypertensive and hypertensive adults.

With each cardiac contraction, a forward pressure wave is generated causing radial expansion of the vessel (that is potential energy of pressure). A portion of the ejected stroke volume ( $\sim 40 \%)$ is temporarily stored within the elastic vessel wall, and upon cardiac relaxation the vessel recoils and stored blood is imparted back to the systemic circulation (that is kinetic energy of flow). When proximal aortic inflow exceeds terminal outflow capacity, the distension caused by the rise in volume generates a concomitant rise in pressure (that is reservoir pressure). With advancing age and subsequent loss of arterial compliance, pressure in the arterial reservoir rises more rapidly for a similar increase in volume ${ }^{13}$ significantly contributing to age-associated changes in contour of the BP waveform. The capacitance function of the arterial tree ensures adequate runoff during diastolic decay to the periphery and almost completely explains the exponential reduction in pressure during diastole (when the aortic valve is closed and there is no inflow). Indeed, change in reservoir pressure in the current study was significantly associated with the change in DBP contour.

To our knowledge, this is the first study to examine the effect of an exercise intervention on reservoir pressure. Compared with control conditions, we noted reductions in reservoir pressure following RET. Changes in reservoir pressure were associated with changes in both SBP and DBP. Reservoir pressure is proportional to the volume of blood stored in the aorta, which in turn depends on the interactions of systemic arterial compliance and impedance to outflow. ${ }^{13}$ The effect of RET on arterial compliance remains controversial with some studies noting reductions in compliance/increases in stiffness ${ }^{34,35}$ and others noting no change. ${ }^{6,36,37}$ RET has been shown to reduce arteriolar myogenic tone and peripheral vascular resistance $(\mathrm{PVR})^{6,38}$ and this can occur irrespective of changes in large artery stiffness. ${ }^{34}$ Favorable changes in reservoir function can occur concomitant with increases in arterial stiffness $^{39}$ and this may be due to changes in PVR offsetting changes in arterial stiffness. Thus, it is possible that reductions in PVR and arteriolar tone with RET may alter terminal impedance enabling greater runoff into peripheral microvascular beds during diastole (outflow $>$ inflow) leading to sustained reductions in reservoir pressure. ${ }^{40}$

We also noted reductions in $\mathrm{Pf}$ and other proxies of $\mathrm{Pf}\left(P_{1}\right.$ height and excess wave pressure $)^{41}$ following RET. Changes in these pressure components were also associated with changes in aortic SBP. Pf is influenced by $Z_{c}$ (the association of regional pressure and flow in the proximal aorta) as well as transverse impedance (reservoir function or capacitance owing to radial expansion of the vessel). Thus, alterations in terminal and transverse impedance may subsequently have a favorable effect on upstream $\mathrm{Zc}$ contributing to reductions in Pf. This is important, given that increases in Pf with advancing age 
contribute significantly to age-associated increases in BP. ${ }^{11}$ RET may be a useful lifestyle intervention to favorably modify this important hemodynamic parameter.

Whether RET influences aortic Zc remains unknown. RET has been shown to increase aortic stiffness in older prehypertensive and hypertensive adults. ${ }^{34}$ An inherent limitation of measuring aortic stiffness (via pulse wave velocity) is that proximal aortic mechanical properties are neglected. MRI studies have reported heterogeneity in aortic stiffness proceeding from proximal to distal regions. ${ }^{42,43}$ Moreover, changes in aortic stiffness and $\mathrm{Zc}$ with aging and in the presence of hypertension are not uniform. ${ }^{44,45}$ Therefore, disparate change in proximal aortic $\mathrm{Zc}$ and distal aortic pulse wave velocity (PWV) with RET is plausible. Strength-trained athletes have larger ascending aortic diameters; ${ }^{46}$ thus, it is possible that RET may increase aortic root size. It has been suggested that this dilitation helps to offset wall stiffening by maintaining the capacity of the aorta to store volume during systole. ${ }^{42}$ In general, $\mathrm{Zc}=\left(E h / r^{5}\right)^{1 / 2}$, where $r$ is radius, $E$ is Young's elastic modulus and $h$ is wall thickness. As can be seen from this equation, $\mathrm{Zc}$ is modulated substantially by radius (raised to an approximate power of 2.5) and less so by $E$ and $h$ (owing to the square root function). According to the Moens-Korteweg equation, $E=\left(\mathrm{PWV}^{2} \times D \times \rho\right) / h$, thus $\mathrm{PWV}$ is directly proportional to the square root of the wall thickness and indirectly proportional to the square root of the radius. As such PWV is relatively insensitive to diameter, whereas $\mathrm{Zc}$ and volume elastance are highly dependent on diameter and these parameters may change divergently if diameter changes. $^{47}$ RET may not effect vascular wall thickness. ${ }^{35,38,48}$ Therefore, an increase in diameter without a proportional increase in vessel wall thickness would offset an increase in PWV. More research is needed to examine the effects of RET on $\mathrm{Zc}$ in prehypertensive and hypertensive adults.

Similar to previous reports $5,6,35-37,49$ we noted no change in AIx following RET although this is not a universal finding. ${ }^{50}$ AIx as a measure purely attributable to wave reflections has been challenged as factors that influence forward wave genesis and impedance also affect AIx. ${ }^{13,51}$ Therefore, we also employed a more refined measure to quantify pressure from wave reflections using impedance analysis and flow waveform triangulation. Using this novel approach we noted no changes in $\mathrm{Pb}$. Numerous studies have acknowledged the importance of pressure from wave reflections as it relates to age-associated increases in $\mathrm{BP},{ }^{12}$ target organ damage and CVD mortality. ${ }^{25,33}$ Although RET appears able to reduce Pf and reservoir pressure, RET might not be a useful lifestyle intervention to attenuate ageassociated increases in pressure from wave reflections.

Limitations to this study should be acknowledged. Previous studies have reported sex differences in the vascular and BP response to RET. ${ }^{52}$ Given the small sample size of the current study and relatively few men, we lacked statistical power to perform subgroup analyses to adequately explore this possibility. Statistically adjusting for sex did not alter observed findings. In conclusion, RET may be an effective lifestyle intervention to reduce central BP in men and women with prehypertension and hypertension. Reductions in central BP with RET are related to changes in Pf and reservoir pressure, suggesting that capacitance and impedance properties of the arterial system have an important role in governing reductions in BP with RET. RET does not appear to be a useful intervention to reduce pressure from wave reflections in prehypertensive and hypertensive older adults.

\section{CONFLICT OF INTEREST}

The authors declare no conflict of interest.
1 Kelley GA, Kelley KA, Tran ZV. Aerobic exercise and resting blood pressure: a metaanalytic review of randomized, controlled trials. Prev Cardiol 2001; 4: 73-80.

2 Williams MA, Haskell WL, Ades PA, Amsterdam EA, Bittner V, Franklin BA Gulanick M, Laing ST, Stewart KJ. Resistance exercise in individuals with and without cardiovascular disease: 2007 update: a scientific statement from the American Heart Association Council on clinical cardiology and council on nutrition, physical activity, and metabolism. Circulation 2007; 116: 572-584.

3 Cornelissen VA, Fagard RH, Coeckelberghs E, Vanhees L. Impact of resistance training on blood pressure and other cardiovascular risk factors: a meta-analysis of randomized, controlled trials. Hypertension 2011; 58: 950-958.

4 Aronow WS, Fleg JL, Pepine CJ, Artinian NT, Bakris G, Brown AS, Ferdinand KC, Ann Forciea M, Frishman WH, Jaigobin C, Kostis JB, Mancia G, Oparil S, Ortiz E, Reisin E, Rich MW, Schocken DD, Weber MA, Wesley DJ, Harrington RA, Bates ER, Bhatt DL, Bridges CR, Eisenberg MJ, Ferrari VA, Fisher JD, Gardner TJ, Gentile F, Gilson MF, Hlatky MA, Jacobs AK, Kaul S, Moliterno DJ, Mukherjee D, Rosenson RS, Stein JH, Weitz HH. Accf/aha 2011 expert consensus document on hypertension in the elderly: a report of the American college of cardiology foundation task force on clinical expert consensus documents developed in collaboration with the American academy of neurology, American geriatrics society, American society for preventive cardiology, American society of hypertension, American society of nephrology, association of black cardiologists, and European society of hypertension. J Am Soc Hypertens 2011; 5: 259-352.

5 Taaffe DR, Galvao DA, Sharman JE, Coombes JS. Reduced central blood pressure in older adults following progressive resistance training. J Hum Hypertens 2007; 21 96-98.

6 Heffernan KS, Fahs CA, Iwamoto GA, Jae SY, Wilund KR, Woods JA, Fernhall B. Resistance exercise training reduces central blood pressure and improves microvascular function in african American and white men. Atherosclerosis 2009; 207: 220-226.

7 Roman MJ, Devereux RB, Kizer JR, Lee ET, Galloway JM, Ali T, Umans JG, Howard BV. Central pressure more strongly relates to vascular disease and outcome than does brachial pressure: the strong heart study. Hypertension 2007; 50: 197-203.

8 Neisius U, Bilo G, Taurino C, McClure JD, Schneider MP, Kawecka-Jaszcz K, StolarzSkrzypek K, Klima L, Staessen JA, Kuznetsova T, Redon J, Martinez F, Rosei EA, Muiesan ML, Melander O, Zannad F, Rossignol P, Laurent S, Collin C, Lonati L, Zanchetti A, Dominiczak AF, Delles C. Association of central and peripheral pulse pressure with intermediate cardiovascular phenoytpes. J Hypertens 2012; 30 67-74.

9 Roman MJ, Okin PM, Kizer JR, Lee ET, Howard BV, Devereux RB. Relations of centra and brachial blood pressure to left ventricular hypertrophy and geometry: the strong heart study. J Hypertens 2010; 28: 384-388.

10 Wang KL, Cheng HM, Chuang SY, Spurgeon HA, Ting CT, Lakatta EG, Yin FC, Chou P, Chen $\mathrm{CH}$. Central or peripheral systolic or pulse pressure: which best relates to target organs and future mortality? J Hypertens 2009; 27: 461-467.

11 Mitchell GF, Wang N, Palmisano JN, Larson MG, Hamburg NM, Vita JA, Levy D, Benjamin EJ, Vasan RS. Hemodynamic correlates of blood pressure across the adult age spectrum: noninvasive evaluation in the framingham heart study. Circulation 2010; 122: $1379-1386$

12 Namasivayam M, McDonnell BJ, McEniery CM, O'Rourke MF. Does wave reflection dominate age-related change in aortic blood pressure across the human life span? Hypertension 2009; 53: 979-985.

13 Davies JE, Baksi J, Francis DP, Hadjiloizou N, Whinnett ZI, Manisty CH, Aguado-Sierra J, Foale RA, Malik IS, Tyberg JV, Parker KH, Mayet J, Hughes AD. The arterial reservoir pressure increases with aging and is the major determinant of the aortic augmentation index. Am J Physiol Heart Circ Physiol 2010; 298: H580-H586.

14 Bia D, Cymberknop L, Zocalo Y, Farro I, Torrado J, Farro F, Pessana F, Armentano RL. Age-related changes in reservoir and excess components of central aortic pressure in asymptomatic adults. Conf Proc IEEE Eng Med Biol Soc 2011; 2011: 6454-6457.

15 Wang Y, Wang QJ. The prevalence of prehypertension and hypertension among us adults according to the new joint national committee guidelines: new challenges of the old problem. Arch Intern Med 2004; 164: 2126-2134.

16 Zhu H, Yan W, Ge D, Treiber FA, Harshfield GA, Kapuku G, Snieder H, Dong Y. Cardiovascular characteristics in American youth with prehypertension. Am J Hypertens 2007; 20: 1051-1057.

17 Chobanian AV, Bakris GL, Black HR, Cushman WC, Green LA, Izzo Jr. JL, Jones DW, Materson BJ, Oparil S, Wright Jr. JT, Roccella EJ. The seventh report of the joint national committee on prevention, detection, evaluation, and treatment of high blood pressure: the jnc 7 report. JAMA 2003; 289: 2560-2572.

18 Greenlund KJ, Croft JB, Mensah GA. Prevalence of heart disease and stroke risk factors in persons with prehypertension in the united states, 1999-2000. Arch Intern Med 2004; 164: 2113-2118.

19 Qureshi Al, Suri MF, Kirmani JF, Divani AA, Mohammad Y. Is prehypertension a risk factor for cardiovascular diseases? Stroke 2005; 36: 1859-1863.

20 Neisius U, Bilo G, Taurino C, McClure JD, Schneider MP, Kawecka-Jaszcz K, Stolarz Skrzypek K, Klima L, Staessen JA, Kuznetsova T, Redon J, Martinez F, Rosei EA Muiesan ML, Melander O, Zannad F, Rossignol P, Laurent S, Collin C, Lonati L, Zanchetti A, Dominiczak AF, Delles C. Association of central and peripheral pulse pressure with intermediate cardiovascular phenotypes. J Hypertens 2012; 30: 67-74.

21 Agabiti-Rosei E, Mancia G, O'Rourke MF, Roman MJ, Safar ME, Smulyan H, Wang JG, Wilkinson IB, Williams B, Vlachopoulos C. Central blood pressure measurements and antihypertensive therapy: a consensus document. Hypertension 2007; 50: 154-160. 
22 Pauca AL, O'Rourke MF, Kon ND. Prospective evaluation of a method for estimating ascending aortic pressure from the radial artery pressure waveform. Hypertension 2001; 38: 932-937.

23 Adji A, Hirata K, Hoegler S, O'Rourke MF. Noninvasive pulse waveform analysis in clinical trials: similarity of two methods for calculating aortic systolic pressure. $\mathrm{Am} \mathrm{J}$ Hypertens 2007; 20: 917-922.

24 Westerhof BE, Guelen I, Westerhof N, Karemaker JM, Avolio A. Quantification of wave reflection in the human aorta from pressure alone: a proof of principle. Hypertension 2006; 48: 595-601.

25 Wang KL, Cheng HM, Sung SH, Chuang SY, Li CH, Spurgeon HA, Ting CT, Najjar SS, Lakatta EG, Yin FC, Chou P, Chen $\mathrm{CH}$. Wave reflection and arterial stiffness in the prediction of 15-year all-cause and cardiovascular mortalities: a community-based study. Hypertension 2010; 55: 799-805.

26 Nichols WW, Conti CR, Walker WE, Milnor WR. Input impedance of the systemic circulation in man. Circ Res 1977; 40: 451-458.

27 Westerhof N, Sipkema P, van den Bos GC, Elzinga G. Forward and backward waves in the arterial system. Cardiovasc Res 1972; 6: 648-656.

28 Mitchell GF. Clinical achievements of impedance analysis. Med Biol Eng Comput 2009; 47: 153-163.

29 Westerhof N, Westerhof BE. Wave transmission and reflection of waves 'the myth is in their use'. Artery Res 2012; 6: 1-6.

30 Sharman JE, Davies JE, Jenkins C, Marwick TH. Augmentation index, left ventricular contractility, and wave reflection. Hypertension 2009; 54: 1099-1105.

31 Aguado-Sierra J, Alastruey J, Wang JJ, Hadjiloizou N, Davies J, Parker KH. Separation of the reservoir and wave pressure and velocity from measurements at an arbitrary location in arteries. Proc Inst Mech Eng H 2008; 222: 403-416.

32 Staessen JA, Wang JG, Thijs L. Cardiovascular protection and blood pressure reduction: a meta-analysis. Lancet 2001; 358: 1305-1315.

33 Vlachopoulos C, Aznaouridis K, O'Rourke MF, Safar ME, Baou K, Stefanadis C. Prediction of cardiovascular events and all-cause mortality with central haemodynamics: A systematic review and meta-analysis. Eur Heart J 2010; 31: 1865-1871.

34 Collier SR, Kanaley JA, Carhart Jr. R, Frechette V, Tobin MM, Hall AK, Luckenbaugh AN, Fernhall B. Effect of 4 weeks of aerobic or resistance exercise training on arterial stiffness, blood flow and blood pressure in pre- and stage-1 hypertensives. J Hum Hypertens 2008; 22: 678-686.

35 Miyachi M, Kawano H, Sugawara J, Takahashi K, Hayashi K, Yamazaki K, Tabata I, Tanaka $\mathrm{H}$. Unfavorable effects of resistance training on central arterial compliance: A randomized intervention study. Circulation 2004; 110: 2858-2863.

36 Casey DP, Pierce GL, Howe KS, Mering MC, Braith RW. Effect of resistance training on arterial wave reflection and brachial artery reactivity in normotensive postmenopausal women. Eur J Appl Physiol 2007; 100: 403-408.

37 Casey DP, Beck DT, Braith RW. Progressive resistance training without volume increases does not alter arterial stiffness and aortic wave reflection. Exp Biol Med 2007; 232: 1228-1235.

38 Anton MM, Cortez-Cooper MY, DeVan AE, Neidre DB, Cook JN, Tanaka H. Resistance training increases basal limb blood flow and vascular conductance in aging humans. J App/ Physiol 2006; 101: 1351-1355.
39 Levenson JA, Simon AC, Fiessinger JN, Safar ME, London GM, Housset EM. Systemic arterial compliance in patients with arteriosclerosis obliterans of the lower limbs. Observations on the effect of intravenous propranolol. Arteriosclerosis 1982; 2: 266-271.

40 Parker KH, Alastruey J, Stan GB. Arterial reservoir-excess pressure and ventricular work. Med Biol Eng Comput 2012; 50: 419-424.

41 Wang JJ, O'Brien AB, Shrive NG, Parker KH, Tyberg JV. Time-domain representation of ventricular-arterial coupling as a windkessel and wave system. Am J Physiol Heart Circ Physiol 2003; 284: H1358-H1368.

42 Hickson SS, Butlin M, Graves M, Taviani V, Avolio AP, McEniery CM, Wilkinson IB. The relationship of age with regional aortic stiffness and diameter. JACC Cardiovasc Imag 2010; 3: 1247-1255.

43 Nelson AJ, Worthley SG, Cameron JD, Willoughby SR, Piantadosi C, Carbone A, Dundon BK, Leung MC, Hope SA, Meredith IT, Worthley MI. Cardiovascular magnetic resonance-derived aortic distensibility: Validation and observed regional differences in the elderly. J Hypertens 2009; 27: 535-542.

44 Mitchell GF, Lacourciere Y, Ouellet JP, Izzo Jr JL, Neutel J, Kerwin LJ, Block AJ, Pfeffer MA. Determinants of elevated pulse pressure in middle-aged and older subjects with uncomplicated systolic hypertension: the role of proximal aortic diameter and the aortic pressure-flow relationship. Circulation 2003; 108: 1592-1598.

45 Segers P, Rietzschel ER, De Buyzere ML, Vermeersch SJ, De Bacquer D, Van Bortel LM, De Backer G, Gillebert TC, Verdonck PR. Noninvasive (input) impedance, pulse wave velocity, and wave reflection in healthy middle-aged men and women. Hypertension 2007; 49: 1248-1255.

46 D'Andrea A, Cocchia R, Riegler L, Scarafile R, Salerno G, Gravino R, Vriz O, Citro R, Limongelli G, Di Salvo G, Cuomo S, Caso P, Russo MG, Calabro R, Bossone E. Aortic root dimensions in elite athletes. Am J Cardiol 2010; 105: 1629-1634.

47 Mitchell GF. Impedance progress: aortic diameter rears its head again? Hypertension 2007; 49: 1207-1209.

48 Rakobowchuk M, McGowan CL, de Groot PC, Bruinsma D, Hartman JW, Phillips SM, MacDonald MJ. Effect of whole body resistance training on arterial compliance in young men. Exp Physiol 2005; 90: 645-651.

49 Kingsley JD, Figueroa A. Effects of resistance exercise training on resting and postexercise forearm blood flow and wave reflection in overweight and obese women. $J$ Hum Hypertens 2012; 26: 684-690.

50 Cortez-Cooper MY, DeVan AE, Anton MM, Farrar RP, Beckwith KA, Todd JS, Tanaka H. Effects of high intensity resistance training on arterial stiffness and wave reflection in women. Am J Hypertens 2005; 18: 930-934.

51 Heffernan KS, Sharman JE, Yoon ES, Kim EJ, Jung SJ, Jae SY. Effect of increased preload on the synthesized aortic blood pressure waveform. J Appl Physiol 2010; 109: 484-490.

52 Collier SR, Frechette V, Sandberg K, Schafer P, Ji H, Smulyan H, Fernhall B. Sex differences in resting hemodynamics and arterial stiffness following 4 weeks of resistance versus aerobic exercise training in individuals with pre-hypertension to stage 1 hypertension. Biol Sex Differ 2011; 2 : 9. 